\title{
La libertad vigilada. En torno a la invención del juego educativo en España
}

\author{
The freedom that is guarded. Around the invention of \\ the educational game in Spain
}

Xavier Torrebadella* $y$ Jordi Brasó ${ }^{* *}$

Recibido: 23 de febrero de 2021 Aceptado: 4 de mayo de 2021 Publicado: 31 de enero de 2022

To cite this article: Torrebadella, X. y Brasó, J. (2022). La libertad vigilada. En torno a la invención del juego educativo en España. Márgenes Revista de Educación de la Universidad de Málaga. 3(1), 25-44

DOI: http://dx.doi.org/10.24310/mgnmar.v3i1.12795

\section{RESUMEN}

En los regímenes escolares y disciplinares de la educación física del s. XIX los juegos fueron dispositivos de sociabilización para transmitir la ideología de la sociedad dominante. La aportación inspecciona el orden educativo y lúdico de la escuela y de cómo se han expandido los juegos populares y tradicionales afines a la burguesía. $E l$ pre-texto sobre el juego infantil sirve para profundizar un análisis del pasado que cuestiona los usos socioeducativos de los juegos en el presente. La metodología se ha basado en la revisión crítica y análisis hermenéutico de los textos decimonónicos y de inicios del s. XX. Como resultado, se permite cuestionar el relato académicamente acomodado a los intereses de la educación física como asignatura escolar. Se concluye que la escuela ha matado el juego, al aceptar un proceso de deportivización que anula la libertad humana y somete las conductas a las lógicas impuestas por los mercados y el consumo.

Palabras clave: juegos corporales; infancia; educación física; siglo XIX

\section{ABSTRACT}

In the school and disciplinary regimes of physical education of the s. Games were socialization devices to transmit the ideology of the dominant society. The contribution inspects the educational and playful order of the school and how popular and traditional games related to the bourgeoisie have expanded. The pre-text on children's play serves to deepen an analysis of the past that questions the socio-educational uses of games in the present. The methodology has been based on the critical review and hermeneutical analysis of nineteenth century and early-s. XX. As a result, it can question the account academically accommodated to the interests of physical education as a school subject. It is concluded that the school has killed the game, by accepting a process of sportsmanship that annuls human freedom and subjects' behaviors to the logic imposed by markets and consumption.

Keywords: body games; childhood; physical education; 19th century

*Xavier Torrebadella 0000-0002-1922-6785 Universitat Autònoma de Barcelona (España) xtorreba@gmail.com
**Jordi Brasó 0000-0002-3582-9826

Universitat Autònoma de Barcelona (España)

jbrasorius@ub.edu 


\section{INTRODUCCIÓN}

No hay duda de que los juegos motores desde la infancia han contribuido a configurar el carácter y la sociabilización de los adultos. Sin embargo, entre el juego y el no juego siempre ha permanecido una divergencia consustancial a la vida misma que ha personificado los momentos y lugares obligados destinados al trabajo o al estudio, de aquellos libres que pertenecen al placer y la diversión.

La razón de profundizar sobre las connotaciones educativas y sociales que se depositan en los juegos tradicionales y populares sirve para re-conocer la memoria de una historia colectiva poco visibilizada. Sobre esta concepción, y a través de indagar en los juegos infantiles, es donde podremos encontrar las tipografías de una genealogía atávica sobre las que se ha edificado la sociedad moderna y los dispositivos lúdicos que inventó para garantizar su supervivencia.

Entre estos dispositivos lúdicos se encuentra el paradigma del juego educativo que en el devenir de la pedagogía moderna todavía presenta una cuestión sin resolver, a saber, el grado de autonomía de las personas (infancia y juventud) que juegan y el grado de vigilancia o de control al que se ven sometidas. Para solucionar este problema nació el llamado dispositivo de la libertad vigilada, una forma saber/poder y de abuso pedagógico sobre la emancipación y el empoderamiento personal.

Por lo tanto, en este artículo va a problematizar el orden educativo y lúdico de la escuela y de cómo la sociedad ha desplegado juegos populares y tradicionales como dispositivos de sociabilización burguesa que se han ido transmitiendo de generación en generación. Asimismo, se declara cómo la escuela ha matado el juego y, a través de aceptar el proceso de deportivización moderno, ha convertido la libertad humana en un dispositivo de control represivo y disciplinado de las conductas, sometido a las lógicas depredadoras de la supremacía capitalista.

La metodología se ha basado en el análisis de los textos y fuentes primarias, que han sido contextualizados con fuentes secundarias. Todo ello se ha tratado a partir de un modelo hermenéutico que ha permitido entender parte de una época histórica. Los resultados muestran este control escolar del hecho lúdico, que ha ido apareciendo en diferentes momentos temporales y que actualmente se está apoderando también de la vida pública. La libertad, por lo tanto, va quedando progresivamente reducida en todos los campos y el control de nuestras conductas y nuestras formas de pensar están adaptadas y condicionadas en la cotidianidad.

\section{METODOLOGÍA}

De las diversas metodologías para el análisis histórico (Brasó, 2017, 2018a, 2018b; Brasó, Torrebadella, 2018, 2020; Torrebadella, 2017), para el caso que nos ocupa, se ha empezado con una primera fase de revisión documental histórica sobre el juego a través de las fuentes primarias localizadas en las hemerotecas y bibliotecas digitales españolas. La hemeroteca de referencia ha sido la Hemeroteca Digital de la Biblioteca Nacional de España. Asimismo, las bibliotecas particulares de los autores han contribuido a la extracción de la información. En la construcción del relato analítico se ha utilizado el texto histórico como instrumento de prueba —o dato tangible — para sostener la validación de la autenticidad. Estos textos o citas literales tienen una significativa razón para justificar la interpretación hermenéutica, que de otro modo parecería artificiosa o poco 
evidenciada. La fuente primaria del texto histórico es el dato que revela el valor cualitativo del estudio; es decir, lo que son los números o porcentajes en estudios de índole cuantitativa.

\section{BREVE APORTACIÓN HISTÓRICA}

La forzada connaturalización del juego en el régimen de las disciplinas escolares ha configurado desde antaño el modus operandi de las llamadas renovaciones pedagógicas. La idea del juego en la escuela no es cosa nueva (Bantulà, 2006, 2008; De Borja, 1984; Payà, 2007). La máxima de Horacio de "enseñar deleitando" (Bantulà, 2010), también ha sido inteligentemente utilizada para la construcción política del Estado.

En la Grecia antigua, la paideia ya tenía por objeto el endurecimiento físico — también mental - y el alcance de la virtud en la vida comunitaria en la pólis — con una búsqueda también de un entrenamiento retórico para los combates dialectales en las calles, gimnasios y ágoras-. En la escuela de la Grecia antigua no se jugaba, se formaban potenciales guerreros y ciudadanos —civilizados_- Pasa de modo similar con el modelo militar lacedemónico que buscaba la agogé espartana. Grecia, y en concreto Atenas y Esparta, buscaban esta excelencia, la areté, a partir de la educación y la formación (Brasó y Garcia, 2019).

Y fuera de la educación griega, había muchas recreaciones y algunas han llegado hasta la actualidad (Andreu, 2009). El elemento lúdico recuperado por los humanistas con un fundamento didáctico renovador es el que ha llegado hasta nuestros días. No hay duda de que la intención de estos humanistas fue el de hacer más agradable y completa la educación de los jóvenes, pero había una intencionalidad pedagógica más profunda, que si bien se conceptualizaba en el concepto aristotélico de la eutrapelia (Vilanou \& Bantulà, 2013), ponía las bases sociales para institucionalizar una educación pública (Torrebadella \& Brasó, 2018).

El humanismo de Erasmo de Róterdam (1466-1536) y de Juan Luis Vives (1492-1540) otorgaron al juego la dimensión didáctica moderna o, mejor dicho, la utilización del juego como dispositivo educativo para una vida honesta. Es en el juego, como apuntaba Erasmo en De civilitate morum puerilium (1530), donde mejor se van a observar las naturalezas personales de los niños, de aquí el especial interés que debe tener el adulto o el maestro para observar estos juegos, puesto que a partir de ellos descubrirá y podrá guiar a sus discípulos por donde mejor les convenga. $\mathrm{Y}$, además, la observación del juego no estaba exenta de la intervención del adulto con el objeto de dirigir las conductas hacia una honesta participación, es decir, al juego moderado y limpio. Esta condición didáctica de lo lúdico se incrustaba para proceder al deleite de los aprendizajes escolares, intelectuales, físicos y morales. Por supuesto, Juan Luis Vives, el conspicuo discípulo de Erasmo es quien mejor recabó en Linguae latinae exercitatio o Dialogos (1539) el sentido eutrapélico y didáctico del juego para la pedagogía moderna (Renson, 1982).

Esta construcción del juego cambió por completo hacia finales del siglo XVIII en la ideología filantrópica de la educación prusiana. Johann Christoph Friedrich Guts Muths (1759-1839) fue su principal creador y su influencia se extendió por todo occidente (Mosse, 2000). Esto sucedía en el delirio de los imperialismos decimonónicos y en una coyuntura de escalada bélica. La lógica del ludus pro patria — divisa de la Union des Sociétés Françaises de Sports Athlétiques (USFSA) - se había instalado en la cultura de las civilizaciones; es decir, en las mentalidades y en los 
imaginarios colectivos de unas sociedades siempre amenazadas por viejos enemigos y, cuando no, había quien se encargaba de inventarlos (Torrebadella, 2015, 2017, 2018): "Casi todos los jóvenes apetecen estar en continuo movimiento [...] conviene; proporcionarles varios juegos [...] en que se habitúen dulcemente a competir con sus iguales, y a pensar y formar raciocinios ajustados. (Anónimo, 1798, p. 188)

A lo largo del proceso de civilización, los juegos prohibidos - o de paideia que citaba Caillois (1986) - han configurado significativos dispositivos de censura y de represión social (Elschenbroich, 1979; González, 1993). Ello venía por la cultura patriarcal (religiosa-militar) hegemónica, responsable principal de inocular desde la familia y la escuela los dispositivos de dominación sobre las naturalezas biológicas de la infancia. En parte, fue la obra de Erasmo De civilitate morum puerilium (1530) quien quebró las libertades de la infancia (Erasmo de Rotterdam, 2006).

Y, en este punto, en el caso de España, la pedagogía llegó con la entrada de la obra del suizo Enrique Pestalozzi (1746-1827) y su consagración al constituir una institución educativa moderna, el Real Instituto Militar Pestalozziano (RIMP, 1806-08) de Madrid. Como mencionaba Francisco Zea, se "estableció en Madrid, a pesar de las circunstancias tan contrarias a toda idea liberal, una escuela de Pestalozzi” (Zea,1806, p. 145). Fue entonces, cuando se desplegó una conciencia sobre desacertados usos escolares y sus violencias físicas de "la letra con la sangre entra". Como es conocido, en esta escuela fue cuando el capitán Francisco Amorós (1770-1848) ensayó sus primeras clases de educación física ofreciendo a los jóvenes los "medios para ejercitarse en juegos que contribuyen a mantener el cuerpo con agilidad y robustez" (El Maestro desengañado, 1897, pp. 42-43). Por lo tanto, los juegos (Real Instituto Militar Pestalozziano, 1807, p. 95) o los llamados “juegos gimnásticos” (El M. T., 1807, p. 86; F. D. O, 1807, p. 118), estuvieron presentes en aquellas primeras clases de la educación física moderna. Como ya se ha dicho, estos juegos muy probablemente fueron aquellos que Guts Muths (1796) puso en práctica en el Philantropinum de Schnepfenthal (Llorens \& Torrebadella, 2017; Quitzau, 2012; Torrebadella, 2013).

Las represiones y las censuras burguesas y católicas sobre el juego no solamente han limitado el desarrollo psíquico, sino también el intelectual. El mismo Pestalozzi ponía énfasis en este asunto, al considerar que los juegos de los niños debían tener, algo más que una mera función gimnástica:

Aquí inclusive podemos validar los propósitos de la gimnástica escolar que fue técnicamente concebida para adoctrinar y formar unas elites de ciudadanos "como buenos defensores de la patria” (Fernández Sirvent, 2010, p. 81). Así, la gimnástica de Amorós alojaba una doble intención, que más allá del desarrollo físico, tenía el propósito de ejercer el control y poder social de las futuras generaciones dirigentes. En este orden no fue menor la dimanación de los dispositivos de poder de las instituciones médicas y sus intervencionistas discursos fundacionales de la educación física escolar (Vicente-Pedraz \& Torrebadella-Flix, 2017).

De aquí que se inventarán una infinidad de juegos motores que fueron investidos de valor pedagógico para la recreación y la formación del carácter. Desde entonces, los juegos de patio en la educación física o en el recreo fueron recomendados por la inspección escolar (Avendaño \& Carderera, 1850; Figuerola, 1844), jugar significaba ejercitar el cuerpo, el ingenio, pero también someterse a la moral dominante. Sin duda, solamente había que jugar a los juegos permitidos 
y, siempre, delante del maestro observador. Por lo tanto, las suspicacias por los juegos libres en las escuelas preocupaban profundamente a educadores y padres de familia (TorrebadellaFlix \& Vicente-Pedraz, 2016). Los tratados de juegos infantiles decimonónicos son ejemplo de este proceso. El proceso de pedagogización del juego, o ludificación (Caillois, 1986) — de la domesticación a partir de la paideia - siempre ha estado sujeto a los intereses del poder (Elschenbroich, 1979). Por ejemplo, los juegos imaginarios bélicos nunca han estado prohibidos y siempre se han cultivado sus intereses. Solamente hay que ver cómo en los colegios, y especialmente en los religiosos, se adiestraban a los alumnos en las destrezas de la esgrima, el boxeo, los ejercicios militares y otros juegos de combates. En este contexto el fútbol era una expresión genuina remozada de modernidad.

La intervención del maestro, la vigilancia, el control y la orientación de los juegos sobre un fin moral y prejuicioso era el signo del buen quehacer educativo. Así se pronunciaba el inspector de enseñanza Mariano Carderera (1815-1893): "Hacen muy mal los maestros que abandonan a los niños en las horas de recreo [...] Presencie el maestro estas diversiones y aun tome parte en ellas" (Carderera, 1855, p. 220)

No obstante, la percepción de la idea de libertad, asociada al juego, es fundamental para entender el grado de manipulación a la que estaba sometida la infancia en la llamada buena educación. Se buscaba así un control, pero de manera oculta y simulando que no había tal vigilancia, sino una libertad lúdica.

Singularmente, esta buena educación distaba mucho de la que recibían las clases populares. El doctor Pere Mata i Fontanet (1811-1877), político liberal republicano y destacado intelectual, expresó una elocuente representación del juego infantil: "Los chicos no saben estarse quietos [...] Para todo lo que sea ejercicio, movilidad muscular, allí están ellos, el espíritu de destrucción los anima; nada está seguro en sus manos" (Mata, 1858, p. 235)

El dispositivo disciplinario en la idea de panóptico de Bentham (1822) ya fue proporcionado en 1762 por Jean-Jacques Rousseau (1712-1778), en El Emilio, cuando sostenía vigilar el mundo de los niños, es decir, sus juegos, sin que se dieran cuenta de ello, creando así una ilusión de falsa libertad.

Por su parte, Bentham argumentaba una vigilancia represiva, es decir, una observación guardiana constante y oculta sobre los individuos que saben que son vigilados (Foucault, 2012). Por lo tanto, de aquí viene la necesidad de crear campos de juego para proteger y controlar a los niños y sus juegos.

El juego libre situado en el goce fue al parecer erradicado de la escuela. El juego dirigido instalado en el lugar de la producción y la utilidad fue inventado en la escuela moderna (Herrera \& Buitrago, 2010, p. 70)

Jugar en libertad quiere decir entonces, que se puede jugar, pero solamente en aquellos juegos consentidos y, entre estos, aquellos que satisfacían al desarrollo físico y a los preceptos de la higiene. Por lo tanto, cuando encontremos declaraciones como las que siguen, deberíamos de sospechar de la verdadera intencionalidad de la declaración sobre la completa libertad (Barrau, 1860, p. 170). 
De igual modo, las orientaciones para los maestros sobre cómo se hacen los niños atrevidos y temerarios, tenían en los juegos y los ejercicios gimnásticos dirigidos el mejor corrector de las imprudencias. Con lo cual se reprimía toda iniciativa impetuosa que naciera de la propia libertad de los menores (C. P., 1860, p. 742):

De aquí vendrían los temores de los progenitores en torno a ciertos juegos y ejercicios gimnásticos vinculados a los aparatos (Vicente-Pedraz \& Brozas-Polo, 2017), como muy bien podían ser los famosos pórticos (gimnasios) al aire libre, por el riesgo de provocar lesiones irreparables. No obstante, la sociedad burguesa decimonónica percibió otros peligros que asociados a las mitologías de la degeneración vieron en la gimnástica, los juegos y otras ejercitaciones físicas los elementos preventivos que garantizaban el saludable desarrollo físico y moral de la infancia y la juventud (Torrebadella-Flix \& Vicente-Pedraz, 2016).

A partir de las primeras noticias sobre el método de jardines para niños de Friedrich Froebel (1782-1852) se imprimió una inflexión en las escuelas de párvulos (A.P., 1861). Así se podía contemplar la propuesta de juegos libres, que el niño escoge libremente en el recreo — “saltar, brincar, jugar al peón, a la pelota, etc., o reposar a su placer” (García, 1874, p. 123)—, o bien, los otros juegos organizados, en los cuales todos los niños participen en la acción. Estos últimos, precisamente, constituían los ejercicios gimnásticos lúdicos de Froebel. Eran movimientos sencillos que imitaban las acciones de la vida rutinaria y laboral con el acompañamiento de cantos. Estos movilizaban toda la musculatura a través de una "gimnástica natural" de ejercicios de marchas, contramarchas, corros y otras variaciones de grupo siempre organizadas con "animación y alegría” (García, 1874, p. 124). Eso sí, con la condición de "que no han menester de aparatos, los cuales suelen ofrecer peligros, y aún los más sencillos asustan o infunden recelos a las madres” (García, 1874, p. 123). Era clave que "bueno fuera que nuestro gobierno siguiera al francés” (García, 1874, p. 124). y diese importancia a la gimnástica.

El mismo Pedro de Alcántara García Navarro (1842-1906) puso énfasis en la técnica procedimental para dirigir los juegos y los aprendizajes escolares; él mismo remarcó en cursiva las claves del éxito:"los juegos aprovechados con inteligencia, se puede conducir muy bien al niño [...] Claro es que para conseguir esto, se necesita mucha observación [...]. Porque ha de tenerse en cuenta, que para que el juego [...] necesita ser libre, y [...] vigilado. [...] las madres no abdiquen el cuidado de dirigir los juegos (García, 1878, p. 102).

No obstante, el rechazo de Froebel (1782-1852) fue serio entre los representantes de la educación católica que vieron en sus ideas un exceso de materialismo (González-Agàpito, 1991). Entre estos se encontraba el maestro de párvulos Julián López Catalán (1834-1890) que, si bien fue uno de los primeros en recomendar a Froebel, mostró reparos puesto que el método mostraba un “espíritu anti-católico" (López Catalán, 1866, 1887, p. 32). Se acusó a Froebel de sustentar, lo que los católicos consideraban tres errores capitales: "que el niño es naturalmente bueno; que la educación consiste en dejar obrar el ser racional; que la libertad y la espontaneidad del educando deben respetarse siempre” (López Catalán, 1887, p. 78).

Por lo tanto, los juegos educativos servían exclusivamente como un medio de moralización religioso. Por esto la necesidad de observar los juegos libres de los párvulos — con una escrupulosa 
vigilancia inadvertida por estos-, a saber, para descubrir la naturaleza que portan sus vicios y sus inclinaciones. Después venían los juegos organizados más apropiados "bajo las apariencias de un agradable recreo" para configurar el dispositivo de la corrección moral (López Catalán, 1864, p. 155). Julián López Catalán mencionaba que los juegos y distracciones son de necesidad [...] ejercen sobre los educandos una influencia provechosa, y proporcionan a los educadores datos... (López Catalán, 1887, p. 76).

De todos modos, la difusión del método de Froebel en España fue inmediata; se publicaron artículos en las revistas de educación y en 1876 se creó una cátedra de pedagogía aplicada que fue otorgada a Pedro de Alcántara García (Martínez Ruiz-Funes, 2013). En 1879 publicó el Manual Teórico-práctico de Educación de Párvulos, según el método de los Jardines de Infancia de F. Froebel, y que sirvió de orientación a las escuelas de párvulos del Estado. Hay que destacar que Pedro de Alcántara García $(1873,1874,1879)$ fue la persona que más extendió las ideas froelianas y también uno de los principales bienhechores de los juegos corporales (García, 1882).

Ahora bien, sobre los juegos corporales, también hay que poner en contexto a la Institución Libre de Enseñanza (ILE) que igualmente reconoció el método de Froebel. Sin embargo, para Francisco Giner de los Ríos (1839-1915) había un preocupante problema, el de los campos de juego (Giner, 1884, p. 51).

Refractario a la ILE se encontraban los dispositivos lúdicos utilizados por el padre Andrés Manjón (1843-1923), el catedrático de Derecho de la Universidad de Granada, en los que cimentó un currículo oculto en base a un incipiente nacionalcatolicismo que, posteriormente, sirvió para nutrir de argumentos pedagógicos la "Escuela Nueva" del franquismo. Si bien hay quien ha buscado semejanzas de la escuela manjoniana con Froebel (Aguilera, 1898; García del Real, 1900) o quienes le nombraban el “Tolstoi castellano viejo y europeo nuevo a la vez” (Marco, 1899, p. 218), su hiervaloración fue efectiva en el credo católico y utilizado para representar una disyuntiva a la escuela laica.

Sin embargo, la ideología que subyacía en Manjón respondía a los intereses de secta, al integrismo católico incitado por el reverendo sabadellense Félix Sardá (1884) que condenó al liberalismo y la educación laica a herejía. Cuando Manjón intervenía en alfabetización de los pobres, era también para cristianizarlos y españolizarlos —invocarles el sentimiento patrio- y todo eso disfrazado de juegos para aprender la historia patria, eso sí, hidalga, conquistadora y castellana (Brasó \& Torrebadella, 2019; Torrebadella \& Brasó, 2019a).

\section{JUEGOS LIBRES CALLEJEROS Y JUEGOS DIRIGIDOS ESCOLARES}

Pero no hay que olvidar que el auténtico juego se encontraba en la calle; en esos juegos de niños — que mencionaba Santiago Ramón y Cajal (1980) — efectivamente espontáneos y libres, en los que se desenvuelven las circunstancias de los peligros y las violencias. Aquí, por ejemplo, se encontraba el jugar a pedradas y otros tantos juegos prohibidos y reprobados que siempre han estado bajo la sospecha de la sociedad (De Unamuno, 1917; Recio, 1884).

Y como apuntaba el literato Miguel de Unamuno (1834-1936), en el marco de reflexión intelectual que propiciaba la Gran Guerra, los juegos sacaban a relucir cómo la educación de ingle- 


\section{EST UDIOS Y ENSAYOS}

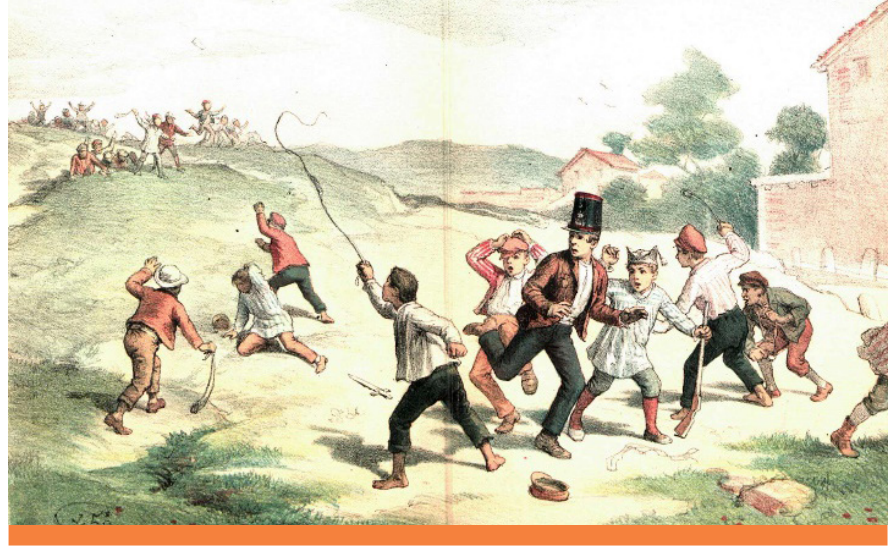

Figura 1. El juego de las pedradas, El Mundo de los niños, 10 de junio de 1888 ses y alemanes afectaba al desarrollo mismo de la contienda: "La gimnasia hecha bajo la dirección de un maestro, los juegos establecidos por una ley por edictos imperiales y sistematizados según principios higiénicos y militaristas para servir a fines militares o burocráticos tienen que contrarrestar los efectos eminentemente morales en la producción del carácter que hacen de los juegos ingleses uno de los grandes pilares de la nacionalidad. (De Unamuno, 1917, p. 6)

De Unamuno, quien criticó el sistema lúdico-educativo del Padre Manjón, manifestaba la diferenciaba aclaratoria y proponía jugar a nuestros juegos y no a los que su maestro decidía o proponía de jugar: "Tuve la fortuna de tener por maestro de primeras letras a un maestro [...] y no a un pedagogo, [...] Y aquel maestro nos dejaba jugar” (De Unamuno, 1917, p. 6)

Efectivamente, el juego de las pedradas o pedreas fue el más popular y legendario entre todos los juegos del siglo XIX [figura 1]. Puede que el juego — desde su lógica externa — representase en sí, la constante beligerancia de la sociedad, es decir, la de una España presa de una aristocracia militar de generales corruptos e insurrectos que no hacían más que inventar negocios de guerra. Naturalmente, la muchedumbre obrera y labriega era la principal víctima de esta situación. No cabe duda, que por mucho que se recriminara y persiguiese la barbarie de las pedreas, este juego, naturalizaba y endurecía el carácter que, en parte, necesitaba el futuro soldado. Ahora bien, este juego era constantemente reprobado por la sociedad, sobre todo, si molestaba al vecindario: "Llamamos la atención de las autoridades sobre las luchas a pedradas por los niños, que todos los días tienen lugar en las afueras de esta población y paseos más frecuentados” (Valls, 1879, p. 3)

El abandono de la educación en España era algo que parecía no preocupar demasiado a los políticos. La Restauración decimonónica no hizo ningún esfuerzo en reformar el sistema educativo, en un tiempo en el que todas las potencias de Europa estaban debatiendo en cómo debería mejorarse de la educación pública. Las propuestas reformistas como las de Rafael María de Labra (1887), apenas producían efecto. Sí, España encabezaba el primer puesto en analfabetismo y los mozos llamados a filas eran los más raquíticos que se podían encontrar. Además, en cuanto a la educación física, sirva la observación del profesor José Sánchez González de Somoano (1883, p. 43): "El estado de la Gimnasia en las demás provincias de España es, con corta diferencia, lo mismo que en Madrid; pero debemos hacer constar que Cataluña ocupa el primer lugar, por lo muy extendida que se halla en sus provincias”.

El controvertido debate sobre los juegos corporales más convenientes en España quedó manifestado en el interesante artículo del Dr. Alejandro San Martín (1889), entonces director de la Escuela Central de Gimnástica (1887-1892), que trató de clarificar las posiciones y tendencias doctrinales del momento (Torrebadella-Flix \& Domínguez, 2018a, 2018b). 


\section{EST UDIOS Y ENSAYOS}

Hacía finales de siglo XIX las preocupaciones profesionales sobre cuál debía ser el carácter con el que había de implementarse la educación física entraba en Europa en un debate de manifestaciones divergentes. Si bien, había tendencias a rechazar los ejercicios gimnásticos de corte militar, los juegos corporales representaban una alternativa que, en un principio, parecía menos beligerante. Sobre estas cuestiones los profesores de gimnástica no tenían ninguna orientación oficial a la que ceñirse. El mismo profesor David Ferrer Mitayna (1893), Catedrático en el Instituto de Barcelona proponía escoger lo mejor de cada método. Este problema fue parcialmente resuelto con la Circular del Director General de Instrucción Pública, Eduardo Vincenti, sobre la enseñanza de la Gimnástica en los Institutos. En esta Circular se aludía que: "hay en la actualidad otro gran movimiento [...] el de los juegos corporales al aire libre y en pleno campo, cultivados con indecible entusiasmo por el pueblo inglés, y que ha hecho de su juventud la más sana y vigorosa de nuestro tiempo”. (Pedregal, 1895, pp. 145-155)

Pero en esta orientación pedagógica, la gimnástica también necesitaba del juego para estimular su práctica. Primero la gimnástica dirigida y, luego el juego libre, “una lección de placer”, dirigidos, pero no mandados, como mencionaba Lagrange (1894, p. 299).

La maestra de las escuelas públicas de Valencia, María Carbonell (1897, p. 328), reclamaba una mayor atención de la educación a través de los juegos y, para este propósito, apelaba a una reforma de los juegos tradicionales por otros más pedagógicos y patrióticos que fueran de provecho para la educación física y moral. También pedía disponer de un espacio conveniente para aplicar esta acción pedagógica.

Aparte, en esta maestra volvemos a encontrar el dispositivo psicológico del juego, que busca observar a los alumnos para descubrir sus inclinaciones y encauzarles hacia las conductas morales propias de su edad y de la sociedad que las determina. No obstante, como trata Carbonell (1897, p. 327), la observación de los juegos para descubrir el campo afectivo que se desenvuelve en cada uno los educandos, solamente se puede conseguir de forma verdadera cuando estos no se sienten vigilados.

Y, sobre todo, la idea que en el juego debe siempre existir un carácter pedagógico subyacente, es decir, socializador y civilizador. Todo ello a través de otorgar espacios de libertad y de la toma de decisiones sobre a qué jugar; incluso se pueden inventar nuevos juegos, pero siempre dispuestos al fin que se propone, sin que los niños y niñas que juegan lo perciban. De aquí que el maestro y la maestra se conviertan en verdaderos expertos del engaño a través del teatro pedagógico sobre el que cada día deben de actuar, en la escuela, el lugar de la función teatral. El salir de la escuela de excursión o los llamados paseos escolares ofrecían momentos oportunos para desahogar el exceso de trabajo intelectual, el inmovilismo de las aulas y el respirar aires más saludables, pero también para recrear esta ilusión de la libertad y del juego:

Al Maestro, pues, le corresponde incitar a sus alumnos en los juegos buscando, entre los que de antiguo se conocen y otros que puede inventar, aquellos que tengan mayor atractivo, que no sean molestos, ofensivos ni pesados y que respondan a un fin pedagógico, sin que los mismos niños se aperciban, por supuesto, de este carácter educativo que al juego se le trata de imprimir. (Arnal, 1897, p. 73) 


\section{EL JUEGO, LA REFORMA EDUCATIVA Y LA INSTITUCIONALIZACIÓN LÚDICA}

En 1900, la crisis del "Desastre" del 98 y la vergüenza española ante la sociedad internacional forzó la creación del Ministerio de Instrucción Pública. Pero este fue una tímida respuesta al problema de la educación, que necesitaba amplias reformas estructurales y también una orientación más acorde a la pedagogía moderna. Esta posición fue defendida por el periódico El Liberal que se implicó en la promoción de un certamen pedagógico sobre “¿Cómo deberían ser los juegos de la infancia?" (Bartolomé, 1900). En esta sección se presentaron significativas aportaciones de Matilde García del Real (1900), Félix Martí Alpera (1900) o Ángel Llorca (1900), también publicados en La Escuela Moderna. La nueva pedagogía se expresaba, por lo tanto, a través de la incorporación del juego libre y educativo — pero siempre bajo la orientación del adulto- como un medio eficaz para la sociabilización, la intelectualización, la moralización, el desarrollo físico y la participación ciudadana en una sociedad democrática (García Del Real, 1900; Taylor, 1900).

Por su parte, Alejandro San Martín (1900, p. 165), siguiendo las teorías del juego de Schiller, mencionaba: "Se dice que no debe convertirse en juego la educación de la infancia; no se instruye jugando, y el estudio es siempre penoso”. La definición de juego para San Martín (1900, p. 165) era "la satisfacción de un impulso innato y placentero a recabar la libertad humana por medio de ejercicios instintivos arbitraria y sencillamente coordinados”.

El maestro Ángel Llorca (1866-1942), miembro de la ILE, sostenía que los juegos podían y deberían ser educativos: "Es preciso convencer a las gentes de que el juego corporal es un derecho de la infancia, y demostrarles lo mucho que a la Patria importa su renacimiento" (Llorca, 1900, p. 38). Sobre este convencimiento citaba que "el niño, para satisfacer la necesidad de ejercicio que naturalmente siente, ha de entregarse al juego en completa libertad; pero el educador incumbe el cuidado de dirigirle sin imposición al cumplimiento del fin educativo" (Llorca, 1900, pp. 38-39), es decir, había que engañar pedagógicamente al niño para orientarle hacia los juegos deseados.

De todos modos, si por su parte Llorca (1900, p. 42) consideraba que el lugar ideal para los juegos de los niños era la propia escuela, admitía que tanto la escuela española como las mismas familias se encontraban incapacitados para ejercer la misión tutelar acerca de la educación de los niños y niñas, y nada podían "hacer sin una amplia y radical reforma". Quedaba claro que "la transformación educativa es una exigencia patria que importa satisfacer a todo trance (Llorca, 1900, p. 44)

Si bien, como mencionaba Matilde García del Real (1856-1932), la principal característica de todos los juegos es la libertad, estos tenían que adaptarse normativamente a las leyes democráticas de los países.

Es, además, el juego en común, escuela de la verdadera democracia y fraternidad humanas, y de la vida tal como debiera ser: en él las distancias sociales se borran, es jefe el que más vale, no el que en más elevada esfera ha nacido. Es también escuela de generosidad, puesto que al vencido se le contenta poniéndole en condiciones de ser á su vez vencedor. (García del Real, 1900, pp. 428-429).

La declaración de García del Real sobre cómo deberían ser los juegos de la infancia, es decir, libres y democráticos, ponía ya en consideración la forma de proceder en la educación física. Por esto, esta maestra pedía patios, jardines y campos idóneos para fomentar el juego libre. Y, ade- 


\section{EST UDIOS Y ENSAYOS}

más, añadía que era necesario atender una educación física obligatoria en todos los grados de la enseñanza, no solamente con la gimnástica, sino también fomentando los juegos nacionales y extranjeros, entre estos últimos, aquellos más acordes con nuestro carácter... "promoverse concursos en que jugadores de cada región española, y aun extranjeros, demuestren y enseñen los juegos característicos de su país” (García del Real, 1900, p. 431).

Ahora bien, tras el "Desastre" del 98, la escuela española se envolvió de un discurso regeneracionista que tenía como principal eje político la nacionalización —españolización y castellanización- de todo el país. A esto se le llamó patriotismo, y los primeros que se atrincheraron a estos dominios, frente a la influencia de la cultura anglosajona y sus modos de educación, fueron los sectores más conservadores y católicos de la sociedad. Con lo cual, se hacía un llamamiento a recuperar y no perder nuestros juegos nacionales incluso desde la misma ILE (Rubio, 1909; Torrebadella-Flix \& Brasó, 2019b). Se proponían “juegos físicos, libres y en común con sus compañeros; y éstos en el campo [...] Los juegos corporales ingleses, sin rival en la edad moderna, tienen por primer fin el endurecimiento del cuerpo (García del Real, 1900, p. 430).

No obstante, la realidad venía a ser la misma; todo permanecía como siempre y las elites gobernantes, de necio orgullo, seguían ignorantes. Estas no se percataban que invertir en educación, en dotar de recursos para mejorar una escuela pública, era la mejor obra de patriotismo que esperaba un pueblo necesitado de políticos inteligentes; esta era la obra magna que habían entendido las naciones más cultas y prosperas. Las palabras de García del Real también lo expresaban así: "Ya sé que para hacer todo esto se necesita tiempo y dinero: la educación y la instrucción son caras, pero devuelven con creces a la Patria lo que en ellas se gasta”(García del Real, 1900, pp. 431-432).

Además, hay que subrayar que sobre este contexto subyacía la amenaza de las jerarquías conservadoras - iglesia católica, monarquía y aristocracia, ejército- que venían problematizando la cuestión de una mistificada necesidad de nacionalizar — españolizar y castellanizar — las masas del país (Torrebadella, 2018). De aquí venían las constantes preocupaciones ante la falta de patriotismo y “de una esencialísima educación militar popular” (Rey, 1900, p. 381). Por lo tanto, se deseaba converger hacia un modelo en el que la escuela-cuartel inculcara, desde la primera escolarización, el amor a la Patria, a la nación y a la Bandera (Brasó \& Garcia, 2019); el respecto a las leyes, la obediencia al principio de autoridad y la pasión por las glorias militares y la milicia:

Unido todo ello a la educación gimnástica, que se emplearía haciendo por encauzar los juegos de los niños a las diversiones de torneos y asaltos (como en Alemania, Inglaterra y Suiza se hace), ejercicios corporales y musculares que desarrollan el cuerpo dándole vigor y fortaleza. (Rey, 1900, p. 383).

No cabe duda, que en estas palabras se delataba el orgullo de un nacionalismo español herido por la vergüenza en la que se perdieron las últimas posesiones coloniales. El ridículo internacional de España era visible, no poseía un ejército técnico e instruido, ni en lo físico, ni en lo intelectual; la supremacía militar española hacía generaciones que se había desvanecido en la más absoluta miseria del casticismo militar y ese "nacionalismo endémico de la cultura militar" (Jensen, 2014, p. 32) se resistía ejerciendo el poder de la violencia. 


\section{EST U D O S Y E N A Y O S}

Las oposiciones a la militarización de la infancia fueron efectivas, en tanto que frenaron la oficialidad real de una enseñanza militar. Si bien, algunos colegios de las congregaciones religiosas fomentaron los juegos de guerra, los ejercicios y paradas militares, batallones infantiles, prácticas de tiro..., la pedagogía moderna se opuso radicalmente a este tipo de enseñanza. Principalmente habría que destacar aquí las escuelas racionalistas afines a la Escuela Moderna de Francisco Ferrer y Guardia (1859-1909) y que idealizaban un antimilitarismo y una visión anarcosindical (Torrebadella, 2016).

No obstante, el problema de cómo debían jugar los niños seguía en el entorno de un debate pedagógico-social de carácter público. Las orientaciones del literato y publicista Gregorio Martínez Sierra (1881-1947) son claves para adéntranos en el asunto: "En la escuela se juega. El maestro, con aire grave, pasea entre los niños. Estos se saben estrechamente vigilados. Adiós espontaneidad, y casi adiós placer del juego. [...] Juego sin libertad es mentira. Juego sin vigilancia es peligro. (Martínez Sierra, 1906, p. 1007)

Esta cuestión no era menor, el mismo Ricardo Rubio y Álvarez, subdirector del Museo Pedagógico Nacional pensionado de estudios en el extranjero — entre 1906 y 1908 — para observar la educación de la Primera enseñanza, entre sus conclusiones manifestó que "enviará el Gobierno a Inglaterra, y también á los cursos breves que organiza en Alemania la Comisión central de juegos populares y de la juventud, pensionados, que estudien su organización” (Rubio, 1909, p. 1395)

A la respuesta de qué juegos debían practicarse, Martínez Sierra (1907, p. 1321) aludía a los que ya se estaban usando habitualmente en España, entre estos, el del marro (Brasó \& Torrebadella, 2015) puesto que todos ellos eran idóneos para la educación física; eso sí, siempre que se vigilasen convenientemente. Además, remarcaba que no eran necesarias las "importaciones exóticas. Con jugar bien nuestros juegos clásicos basta [...] Las condiciones morales. En primer lugar, infinitamente libre, y, al mismo tiempo, infinitamente vigilado” (Martínez Sierra, 1907, p. 1321).

Este autor aludía a una cuestión social esquiva, como era la coeducación. Así mencionaba que los juegos debían ser eminentemente colectivos y sin separación de género, por lo que había que superar las cuestiones tópicas de atracción entre hombres y mujeres. De todos modos, los juegos no tenían que impedir los dispositivos de feminización y masculinización deseados por entonces: "es un crimen de lasa humanidad separar en la infancia lo que ha de estar unido en la vida. [...] que el único feminismo posible y de resultado, es hacer a la mujer lo más mujer posible”. (Martínez Sierra, 1907, pp. 1320-1321).

La idea de que los juegos deben preparar para la vida aparecía de forma consustancial en todos los relatos, no obstante, siempre desde la inalterabilidad del orden social establecido. Con lo cual, el juego se entregaba a modo de dispositivo para la reproducción social (Bourdieu \& Passeron, 1996), incorporando en sí mismo todas las violencias simbólicas que se manejan para ejercer la dominación sobre la infancia y la buena ciudadanía de una sociedad burguesa y conforme: "los juegos, como en toda educación, deben preparar al hombre para la vida. En ellos, como en toda su obra, el educador debe hacer poco y dejar hacer mucho” (Martínez Sierra, 1907, p. 1321).

La perversidad del juego llegó con el modelo constructivista y la psicología conductista que vincularon los aprendizajes escolares al condicionamiento social. En este paradigma, los nuevos 
pedagogos se olvidaron de las sensibilidades emocionales ligadas a la corporalidad del naturalismo pedagógico roussoniano. Y aquí es donde se dimensionó la "Re Pedagógica” del juego, como medio para entrar en la psicología de la infancia y, naturalmente, para intervenir sobre ella: "El juego es el medio mejor de conocer al niño, y por esto puede decirse que el mejor laboratorio paidológico del maestro es el campo de juego” (Blanco, 1919, p. 21).

Aún y el paso del tiempo, se puede apreciar que la controversia sobre la didáctica del juego seguía siendo de actualidad y, más todavía, cuando se pretendía atender a los miles de niños y niñas que se criaban abandonados en el arroyo de madrileño. De aquí que se intentará la creación de unas escuelas al aire libre, dotadas de espacios saludables y con encanto, es decir, con espacios propicios para seducir a través del juego instructivo y, de esta manera, procurar el atenuar los riesgos de una población que era considerada socialmente peligrosa (Andrés-Candelas, 2016). No obstante, las discrepancias de fondo formaban parte de la discusión pedagógica: "La importancia del juego en Pedagogía es muy grande [...] si bien hay una pequeña discrepancia entre algunos autores sobre la forma de verificarlo, pues mientras unos opinan que el juego debe ser completamente libre, otros creen que deben ser juegos pedagógicos” (Roy, 1929, p. 27)

Asimismo, la actitud docente podía optar por dos posiciones. Una era la de observar el juego desde fuera, como un vigilante; $y$, la otra, desde dentro, interviniendo en él y simulando que se es un jugador más:"Para conocer el juego tal y como es, y por tanto para poder dirigirlo, el maestro debe tomar parte activa en él, único medio de poder entrar en íntima relación con sus alumnos. Vigilar simplemente el juego es lo mismo que presenciar la comida sin comer con los niños” (Roy, 1929, p. 28)

De aquí surgía el mito del buen profesor; aquel que participaba directamente en el juego y que trataba de disimular que lo que hacía era organizar y vigilar el juego desde dentro. Asimismo, también lo que se lograba era coartar la verdadera espontaneidad y libertad del alumnado. En verdad, en estas escuelas los niños y las niñas no jugaban, solamente se recreaban en el sentido de romper la rutina del trabajo intelectual y sedentario; algunos maestros y pedagogos, a esto, le llamaron educación física.

\section{CONSIDERACIONES FINALES}

Las barreras y los dispositivos de género han jugado en los juegos de la infancia un significativo imaginario colectivo que a lo largo del tiempo ha desarrollado un cultura depravada y enfermiza - con la trivialización de violencias simbólicas - que perdura en los esquemas mentales ligados a modos de pensar y quehaceres que hoy son continuados en los paradigmas morales y económicos del neoconservadurismo y del neoliberalismo. Por muchas razones pedagógicas que se quieran atribuir al deporte (Merino, Arraiz, \& Sobirón, 2018), este tiene todo su origen en el juego y es depositario de una cultura colonial y depredadora.

Hace varias décadas Vilanou y Betancor (1996, p. 769), sin negar los riesgos siempre amenazadores de la intolerancia y del totalitarismo, apuntaban a la postmodernidad como nuevo horizonte a las posibilidades de lo lúdico y del papel que tendría la escuela en la recuperación de "los valores tradicionales del juego en la formación integral de los individuos”, indicando, que por supuesto, los juegos; "ya sean recuperados del pasado, ya sean forjados al socaire de unos 
imaginarios de nuevo cuño, o surgidos de los imparables avances tecnológicos” contribuirán a hacer al hombre más humano. En cambio, Vicente y Brozas (1996) advertían sobre el poder que ejerce la cultura dominante mediante el dispositivo deportivo y del riesgo de perder lo verdaderamente lúdico, por el progresivo avance de un proceso de deportivización y de colonización social. Sinceramente, los primeros se equivocaron y los segundos acertaron, o al menos esta es nuestra opinión al respecto.

Ambas posiciones nos exhortan hoy a reflexionar sobre cómo la escuela ha prestado sus servicios a los intereses sociales del capitalismo y cómo continúa modelando el acto educativo en función de los intereses; el dispositivo lúdico se convierte en la libertad vigilada; un control social en el que se aprende a contribuir a las prohibiciones de una civilización y no deja espacios para las disidencias. Los juegos de la paideia moderna son dispositivos disciplinares que convierten al que juega en un simple títere carente de verdadera libertad. Y en relación con la libertad de los juegos, hay episodios humanos oscuros como en el campo de concentración Treblinka, donde los nazis "organizaron competiciones de fútbol entre los condenados a muerte, les obligaban a jugar al marro, instituyeron un coro y danzas con los presos” (Grossman, 2017, p. 56).

Ya no hay tiempo de reflexionar: la escuela ha matado el juego. En las grandes ciudades la desaparición de la calle como espacio de juego libre a desaparecido. Y aquí, se encuentra el papel que están jugando muchos profesores de educación física seducidos por el delirio de la innovación tecnológica y la gamificación de los aprendizajes. Los patios escolares hace décadas que se convirtieron en lugares de encierro para solazar un régimen carcelario. Hoy los tiempos son otros y lo lúdico-educativo convierte los recreos en espacios menos libres que antes; todo se regula con intenciones de mejorar la sociabilización, de evitar la inactividad y los conflictos. Y fuera de la escuela, los campos de juego actualmente quedan reducidos a espacios cerrados y vigilados —algunos ya dotados con cámaras de vigilancia_, no exentos muchas veces de conflictos mundanos; la calle es así un espacio lúdico restringido, y siempre lo ha sido.

Es curioso destacar que aparecen juegos como el antiguo patín de los niños, que se adapta incluso al mundo del adulto, como un medio de transporte urbano; los parques gimnásticos para jóvenes y no tan jóvenes para poner bello su cuerpo, estar a la moda y cumplir con los ideales capitalistas del siglo XXI; incluso los drons nos recuerdan a juegos antiguos como la cometa, y algunos e-sports nos rememoran a antiguas competiciones griegas en las que el usuario puede participar y ganar y no solo (ad)mirar, como sucede en los Juegos Olímpicos.

Y con todo, aparece una ciudad vigilada, atrapados en la tecnología, el trabajo y en el ocio de consumo sofisticados y bajo la vigilancia policial del 5G. La sociedad del control social pondrá en juego las conductas de las masas urbanas; hay hombres que se han creído dioses y juegan a los dados con los seres humanos. La sociedad y la escuela imponen un juego que ya nada tiene que ver con el verdadero juego — con la tradición del juego-, ese jugar no es libre, no es espontáneo y es falsamente divertido. No es por lo tanto gratuito que aparezcan nuevos juegos que se escapen de la lógica mercantil y entren en la esfera de lo prohibido, de lo delincuente o criminal, juegos que, si bien son socialmente reprobados, es la misma sociedad la que los ha recreado y alimenta. Por ello, no podemos obviar que en todos los juegos de la infancia socialmente aceptados subyace un carácter represivo: la ausencia de una verdadera libertad, que de algún modo u otro 


\section{EST UDIOS Y ENSAYOS}

estamos obligados a reparar. El mundo lúdico de la infancia nos preparó para aceptar las reglas y conductas del presente.

\section{REFERENCIAS}

A. P. (1861, 8 de octubre). Jardines para niños. La Aurora de la Vida, 203-204.

Aguilera, J. (1898, 1 de diciembre). Don Andrés Manjón. Su obra. La Escuela Moderna, 93, 406-416.

Andrés-Candelas, M. (2016). La construcción socio-histórica de la “infancia peligrosa” en España. Revista Latinoamericana de Ciencias Sociales, Niñez y Juventud, 14(1), 95-106.

Andreu, E. (2009). El juego infantil mediterráneo: Grecia antigua. Aloma, 25, 39-51.

Anónimo (1798, 22 de marzo). Precauciones que se han de tener con la tierna juventud, Semanario de la Agricultura y de las Artes dirigido a los párrocos, 88.

Arnal, S. (1897). Paseos escolares. Pamplona: Imp. Provincial.

Avendaño, J., \& Carderera, M. (1850). Curso elemental de pedagogía. Madrid: Est. Tip. de A. Vicente.

Bantulà, J. (2006). La introducció dels jocs populars i tradicionals en l'educació escolar dels infants. Temps d'Educació, 8, 235-247. https://bit.ly/3vsYcDp

Bantulà, J. (2008). Per una pedagogia del joc: la seva aposta educativa des del segle XIX. Revista Catalana de Pedagogia, 6, 361-380. https://bit.ly/3oVjbvU

Bantulà, J. (2010). En torno al “enseñar deleitando" de Horacio. En A. C. Moreu y E. Prats (coord.), $L a$ educación revisitada: ensayos de hermenéutica pedagógica (p. 59-69). Barcelona: Publicacions i Edicions de la Universitat de Barcelona.

Barrau, T. H. (1860). Influjo de la familia en la educación, o, De la educación pública y privada. Barcelona: Luis Tasso.

Bartolomé, E. (1900, 1 de agosto). El Concurso de “El Liberal”. Escuela Moderna, 113, 113-119.

Bentham, J. (1822). Tratados de legislación civily penal. Madrid: Imp. de Fermín Villalpando.

Blanco, R. (1919). De “Re Pedagógica”. Del juego y de su importancia como medio de educación integral. Unión Ibero-Americana, 20-21.

Bourdieu, P., \& Passeron, J. C. (1996). La reproducción. Elementos para una teoría del sistema de enseñanza. Barcelona: Laia.

Brasó,J. (2017). Historia y pedagogía de la Escuela del Mar (1922-1938). Historia Social y Educación. 6(3), 226-260. doi: http://dx.doi.org/10.17583/hse.2017.2717

Brasó, J. (2018a). Los libros de ajedrez en España (c. 1770-1899): bibliografía histórica. Investigación bibliotecológica, 32(75), p. 47-67. http://dx.doi.org/10.22201/iibi.24488321xe.2018.75.57943

Brasó, J. (2018b). Pere Vergés: escola i ludificació al començament del s. XX. Apunts. Educación física y deportes, 133, p. 20-37. doi: https://doi.org/10.5672/apunts.2014-0983.es.(2018/3).133.02

Brasó, J., \& Garcia, J. (2019). Semblances entre l'agogé lacedemònia i l'educació neoliberal actual. Reflexions per una educació crítica. Temps d'Educació, 56, 17-36. https://bit.ly/3c1CL4C 


\section{EST UDIOS Y ENSAYOS}

Brasó, J., \& Torrebadella, X. (2015). “El marro”, un juego tradicional y popular en la educación física española (1807-1936). Revista Complutense de Educación, 26(3), 697-719. https://doi.org/10.5209/ rev_RCED.2015.v26.n3.44680

Brasó, J., \& Torrebadella, X. (2018). Els textos sobre educació física i esport en la llengua catalana des del 1880 fina al 1938. Llengua i literatura, p. 7-52. doi: https: //doi.org/10.2436/20.2502.01.83

Brasó, J., \& Torrebadella, X. (2019). Integrismo religioso y nacional en España. El ataque contra las escuelas laicas de Andrés Manjón (1910). Paulo Freire. Revista de Pedagogía Crítica, 21, 186-213. https:// doi.org/10.25074/07195532.21.1184

Brasó,J. \& Torrebadella, X. (2020). Dos escuelas de higiene en Barcelona: de Escuela del Mar (1922) y Pere Vergés a Escuela 26 de enero (1943) y Enric Gibert. Revista Española de Educación Comprarada, 36, p. 146-179. https://doi.org/10.5944/reec.36.2020.26995

C. P. (1860, 30 de diciembre). Origen de los malos hábitos. Anales de primera enseñanza: periódico de las escuelas y de los maestros, 2(24), 741-744.

Caillois, R. (1986). Los juegos y los hombres. La máscara y el vértigo. México: Fondo de Cultura Económica.

Carbonell, M. (1897, 1 de mayo). Niños y juegos. La Escuela Moderna, 74, 326-330.

Carderera, M. (1855). Diccionario de educación y métodos de enseñanza. Madrid: Imp. De A. Vicente.

De Borja, M. (1984). El juego como actividad educativa: Instruir deleitando: Barcelona: Ediciones de la Universitat de Barcelona.

De Labra, R. (1887, 20 de junio). La instrucción primaria por el Estado nacional (Discurso pronunciado en el Congreso de Diputados, sesión de 11 de junio de 1887). El Liberal, 5-8.

De Unamuno, M. (1917, 16 de febrero). Juego Limpio. Nuevo Mundo, 6-7.

El M. T. (1807, 22 de enero). Concluye de la Carta anterior. Diario de Madrid, 85-86.

El Maestro desengañado (1807, 11 de enero). Educación. Diario de Madrid, 41-43.

Elschenbroich, D. (1979). El juego de los niños. Estudios sobre la génesis de la infancia. Madrid: Zorro.

Erasmo de Rotterdam (2006). De la Urbanidad en las maneras de los niños (De Civilitate morum puerilium). Edición y comentario de Julia Varela. Madrid: Ministerio de Educación y Ciencia.

Erasmun, D. (1530). De Civilitate morum puerilium. Basileae: in officina Frobeniana.

F. D. O. (1807, 30 de enero). [Sobre el Real Instituto Militar Pestalozziano] Continua de la Carta anterior. Diario de Madrid, 117-118.

Fernández Sirvent, R. (2010). Elitismo cultural y político. El entorno del Instituto Pestalozziano (18051808). En A. Alberola y E. Larriva (ed.), Las élites y la "Revolución de España" (1808-1814). Estudios en homenaje al profesor Gérard Dufour (p. 67-87). Alicante: Universidad de Alicante.

Ferrer, D. (1893, 5 de abril). Ejercicios convenientes a los alumnos de Gimnástica de los Institutos de Segunda Enseñanza. Gaceta de Instrucción Pública, 1009-1010.

Figuerola, L. (1844). Guía legislativa e inspectiva de instrucción primaria, Librería Europea de Hidalgo. Madrid: Imp. Catalana.

Foucault, M. (2012). Vigilary castigar. Nacimiento de la prisión. Madrid: Biblioteca Nueva. 


\section{EST UDIOS Y ENSAYOS}

García del Real, M. (1900, 1 de junio). Lo que deben ser los juegos de los niños. Escuela Moderna, 111, 426 432.

García, P. de A. (1873). Estudio. Acerca de los métodos de enseñanza, con relación a las escuelas de educación primaria (Conclusión). Revista de la Universidad de Madrid, 2(1), 690-717.

García, P. de A. (1874). Froebel y los jardines de la infancia. Madrid: Imp. Est. Aribau.

García, P. de A. (1878, 27 de enero). Los juegos de la infancia bajo el punto de vista de la educación (Páginas de un libro inédito). Revista Europea, 205, 97-102.

García, P. de A. (1882.1 de abril). Los juegos de la infancia bajo el punto de vista de la educación, Instrucción para la mujer, 3, 36-41.

García, Pedro de Alcántara (1879). Manual teórico-práctico de educación de párvulos según el método de los jardines de infancia de F. Froëbel. Madrid: Imp. del Colegio Nacional de Sordo-Mudos y Ciegos.

Giner, F. (1884). Campos escolares. Revista de España, 96, 32-62.

González, J. (1993). Tractatus ludorum. Una antropología del juego. Barcelona: Antrophos.

González-Agàpito, J. (1991). Educación infantil e industrialización en Cataluña. Historia de la Educación, $10,135-154$.

Grossman, V. (2017). El infierno de treblinka. Barcelona: Galaxia Gutenberg.

Guts Muths (1796). Spiele zur übung und erholung des körpers und geistes, fur die jugend. Schnpfenthal: ImVerlage der Buchhandlung der Erziehungsanstalt.

Herrera, C. X., \& Buitrago, B. N. (2010). Juego y escuela en Colombia a finales del siglo XIX. Pedagogía y Saberes, 33, 63-72. https://doi.org/10.17227/01212494.33pys63.71

Jensen, G. (2014). Cultura militar española. Modernistas, tradicionalistas y liberales. Madrid: Biblioteca Nueva.

Lagrange, F. (1894). La higiene del ejercicio en los niños y los jóvenes. Madrid: Lib. de José Jorro.

Linaza, J. L. (2013). El juego es un derecho y una necesidad de la infancia. Bordón. Revista de pedagogía, 65(1), 103-117.

Llorca, A. (1900, 1 de julio). Lo que deben ser los juegos de los niños. Escuela Moderna, 112, 37-44.

Llorens, M., \& Torrebadella, X. (2017). La gimnástica o escuela de la juventud (1807): primer libro de educación física escolar y génesis de un discurso pedagógico. Revista de Investigación en Educación, 15(2), 122-139. https://bit.ly/3bZjCAa

López Catalán, J. (1887). El froebelianismo puro y neto. Barcelona: Juan y Antonio Bastinos.

López Catalán, J. (1866). El arte de educar: curso completo de pedagogía teórico práctica aplicada a las escuelas de párvulos. Vol. III. Barcelona: Bastinos.

López Catalán, J. (1864). El arte de educar: curso completo de pedagogía teórico práctica aplicada a las escuelas de párvulos. Vol. IV (2 ${ }^{\mathrm{a}}$ ed.) Barcelona: Bastinos.

Marco, L. (1899). Las Escuelas de Manjón o del Ave María. Revista Ibero-Americana de Ciencias Médicas, $1(1), 217-221$. 


\section{EST UD IOS Y ENSAYOS}

Martí Alpera, F. (1900, 1 de mayo). Lo que deben ser los juegos de los niños. Escuela Moderna, 110, 362368.

Martínez Ruiz-Funes, M. (2013). La cultura material y la educación infantil en España: el método Froebel (1850-1939) (Tesis Doctoral). Universidad de Murcia: Departamento de Teoría e Historia de la Educación.

Martínez Sierra, G. (1906, 1 de diciembre). Lo que son los juegos de los niños. Mercurio. Revista Comercial Ibero-Americana, 1006-1007.

Martínez Sierra, G. (1907, 1 de noviembre). Lo que son los juegos de los niños. Mercurio. Revista Comercial Ibero-Americana, 1320-1321.

Mata, P. (1858). Tratado de la razón humana. Madrid: Bailly-Balliere.

Merino, A., Arraiz, A., \& Sobirón, F. (2018). De la inherencia histórica del juego motriz al potencial educativo del deporte. Cultura, ciencia y deporte, 38, 175-182. http://dx.doi.org/10.12800/ccd. v13i38.1073.

Mosse, G. L. (2000). La imagen del hombre. La creación de la moderna masculinidad. Madrid: Talasa.

Payà, A. (2004). Joc corporal, esport i educació física a l'ideari pedagògic de la Institución Libre de Enseñanza. Educació i Història, 7, 117-133. https://bit.ly/3foAT82

Payà, A. (2007). La actividad lúdica en la historia de la educación contemporánea. (Tesis doctoral inédita). Valencia: Universidad de Valencia.

Payà, A. (2013). Aprender deleitando: el juego infantil en la pedagogía española del siglo XX. Bordón. Revista de pedagogía, 65(1), 37-46. https://bit.ly/34r3Hq1

Pedregal, F. (1985). La educación gimnástica. Madrid: Imp. de los Hijos de M. G. Hernández.

Pestalozzi, E. (1807). Libros elementales de Pestalozzi. Doctrina de la visión de la relación de los números. Tomo I. Madrid: Imp. Real.

Quitzau, E. A. (2012). El trabajo como alegría juvenil”: la gimnasia según Johann Christoph Friedrich Guts Muths. Revista Brasileira de Ciencias do Esporte, 34(2), 359-373. https://doi.org/10.1590/S0101$\underline{32892012000200008 .}$.

Ramón y Cajal, S. (1980). Mi infancia y juventud. Madrid: Espasa Calpe.

Real Instituto Militar Pestalozziano (1807). Noticia de las providencias tomadas por el Gobierno para observar el nuevo método de la enseñanza primaria de Enrique Pestalozzi, y de los progresos que ha hecho el establecimiento formando en Madrid con este objeto desde su origen hasta el principio del año 1807. Madrid: Imp. Real.

Recio, P. (1884, 14 de marzo). Los juegos de los niños. La Dinastia, 1630-1631.

Renson, R. (1982). Le jeu chez Juan Luis Vives (1492-1540). En Ph. Ariès, J-C. Margolin (ed.), Les jeux à la Renaissance: actes du XXIIIe Colloque international d'études humanistes (p. 469-487). Paris: Vrin.

Rey, C. (1900, 15 de octubre). Educación militar popular. Revista Técnica de Infantería y Caballería, 381384.

Rousseau, J. J. (1821). Emilio, o de la educación -t. II. Madrid: Imp. de Alban y Compañía. 


\section{EST U D I O Y EN SAYOS}

Roy, P. (1929). Planes escolares de la Villa y la Corte. Madrid: Imp. Municipal.

Rubio, R. (1909, 20 y 25 de enero). Primera Enseñanza. Gaceta de Instrucción Pública y Bellas Artes, 13941395.

San Martín, A. (1889). De los juegos corporales más convenientes en España. El Ateneo-revista científica, literaria y artística, 3, 53-75.

San Martín, A. (1900, 1 de marzo). Juegos escolares. La Escuela Moderna, 108, 161-165.

Sánchez, J. (1883). Tratado de gimnasia pedagógica para uso de las escuelas de primera y segunda enseñanza e institutos. Madrid: Imp. de Manuel Minuesa de los Ríos

Sardá, F. (1884). El liberalismo es pecado. Cuestiones candentes. Barcelona: Lib. Tip. Católica.

Taylor, A. R. (1900, 1 de marzo). Los instintos y los juegos de los Niños. La Escuela Moderna, 108, 166-171.

Torrebadella, X. (2013). Gimnástica y educación física en la sociedad española de la primera mitad del siglo $X I X$. Lleida: Servei de Publicacións de la Universitat de Lleida.

Torrebadella, X. (2015). Los batallones infantiles en la educación física española (1890-1931). ODEP. Revista Observatorio del Deporte, 1(1), 32-70. https://bit.ly/3fTEPwm

Torrebadella, X. (2016). Francisco Ferrer Guardia, postmoderno avanzado y precursor de la educación física crítica. Análisis y reflexión para un giro didáctico. Educar, 52(1), 169-191. doi: https://dx.doi. org/10.5565/rev/educar.756.

Torrebadella, X. (2017). La militarización de la educación física escolar. Análisis de dos imágenes publicadas en la prensa de Barcelona de principios del siglo XX. Historia Social y de la Educación, 6(1), 78-108. https://dx.doi.org/10.17583/hse.2017.2393

Torrebadella, X. (2018). “Ludos pro Patria”: Aprender a disparar para salvar la nación. La Razón Histórica. Revista hispanoamericana de Historia de las Ideas, 40, 133-164. https://bit.ly/3hYWGFa

Torrebadella, X., \& Brasó, J. (2018). Mens sana in corpore sano. Sobre la educación del cuerpo en la Contrarreforma española, siglos XVI y XVII. Franciscanum. Revista de las Ciencias del Espíritu, 60(170), 273-328. https://bit.ly/3wFlq9u

Torrebadella, X., \& Brasó, J. (2019a). El patriotismo nacionalizador del padre Andrés Manjón y la «nueva pedagogía católica» en la educación física española (1889-1936). Revista de Estudiosy Experiencias en Educación, 18(36), 137-159. doi: 10.21703/rexe.20191836torrebadella7

Torrebadella-Flix, X., \& Brasó, J. (2019b). Los juegos corporales en la educación física del siglo XIX como preludio al deporte moderno en España. Ciencia, Cultura y Deporte, 14(41), 165-177. https://dx.doi. org/10.12800/ccd.v14i41.1276

Torrebadella-Flix, X., \& Domínguez, J. A. (2018a). El deporte en la educación física escolar. La revisión histórica de una crítica inacabada. Retos: Nuevas Tendencias de la Educación Física y el Deporte, 34, 403-411. https://doi.org/10.47197/retos.v0i34.57963

Torrebadella-Flix, X., \& Domínguez, J. A. (2018b). Las escuelas gimnásticas en España: un enfrentamiento técnico doctrinal en la educación física (1806-1936). Materiales para la Historia del Deporte, 17, 136165. https://bit.ly/2R2i1Cu

Torrebadella-Flix, X., \& Vicente-Pedraz, M. (2016). La gimnástica como dispositivo antionanista en la conformación de la educación física escolar en el siglo XIX en España. El nacimiento de una 


\section{EST UDIOS Y ENSAYOS}

disciplina escolar. Movimento, 22(1), 99-114. doi: 10.22456/1982-8918.53988.

Valls (1879, 2 de marzo). Valls. Diario de Valls, 3.

Vicente, V., \& Brozas, Ma P. (1996). Lo culto, lo no culto y lo popular: la transformación de las prácticas físicas tradicionales ante la cultura dominante. En F. Amador, U. Castro y J. M. Alamo (coord.), Actas del I Congreso Internacional de Luchas y Juegos Tradicionales, Fuenteventura (Islas Canarias) 3-6 de diciembre de 1996 (p. 811-824). Madrid: Impreso por TGA.

Vicente-Pedraz, M., \& Brozas-Polo, M. P. (2017). El triunfo de la regularidad: gimnasia higiénica contra acrobacia en la configuración física escolar en la segunda mitad del siglo XIX. Revista Brasilera do Sporte. 39(1), 49-55. https://dx.doi.org/10.1016/j.rbce.2015.10.006

Vicente-Pedraz, M., \& Torrebadella-Flix, X. (2017). El dispositivo gimnástico en el contexto de la medicina social decimonónica española. De las políticas higiénicas a los discursos fundacionales de la “educación física”. Asclepio, 69(1), p172. https://dx.doi.org/10.3989/asclepio.2017.04

Vilanou, C., \& Bantulà, J. (2013). Sobre la eutrapelia, o la virtud del juego. Moralidad, Historia y Educación. Bordón. Revista de Pedagogía, 65(1), 47-58. https://bit.ly/3vslboI

Vilanou, C., \& Betancor, M. A. (1996). Hombre, juego y trabajo: Aproximación fenomenológica e histórica a la esfera de lo lúdico”. En F. Amador, U. Castro y J. M. Alamo (coord.), Actas del I Congreso Internacional de Luchas y Juegos Tradicionales, Fuenteventura (Islas Canarias) 3-6 de diciembre de 1996 (p. 761-769). Madrid: Impreso por TGA.

Zea, F. (1806, 4 de septiembre). La idea del nuevo de enseñanza de Enrique Pestalozzi. Semanario de Agricultura y Artes, 145-153. 